\title{
PREGNANCY RELATED ANXIETY, COUPLE RELATIONSHIP SATISFACTION AND SUBJECTIVE HAPPINESS AMONG PREGNANT WOMEN
}

\author{
Saira Bano ${ }^{1 *}$, Nazia Iqbal ${ }^{2}$, Sajid M. Alvi ${ }^{3}$, Andleeb Akhtar ${ }^{4}$, Aaliya Zaka ${ }^{5}$ \\ ${ }^{1 * 3,4}$ Department of Psychology, University of Haripur, Pakistan; ${ }^{2}$ Department of Psychology, International Islamic \\ University, Pakistan; ${ }^{5}$ Department of Psychology, Foundation University, Pakistan. \\ Email: "sara.sheraz24@gmail.com
}

Article History: Received on $15^{\text {th }}$ April 2021, Revised on $25^{\text {th }}$ April 2021, Published on $1^{\text {st }}$ May 2021

\begin{abstract}
Purpose of the study: The main purpose of this research was to examine the relationship between pregnancy-related anxiety and couple relationship satisfaction; with the subjective happiness of pregnant women of Pakistan.

Methodology: This study used a quantitative research method, and questionnaires were used for data collection from pregnant women $(N=200)$ of Haripur, Abbottabad, Wah Cantt, and Taxila. The statistical analyses of correlation, regression, t-test, and ANOVAs were used.
\end{abstract}

Main Findings: The results indicated that pregnancy-related anxiety predicts subjective happiness of pregnant women, couple relationship satisfaction positively predicted subjective happiness of pregnant women, and couple relationship satisfaction does not moderate the relationship between pregnancy-related anxiety and subjective happiness among pregnant women.

Applications of this study: The findings have theoretical and applied significance in the term allowing targeting those pregnant women who would benefit from assessment and coping with pregnancy-related anxiety.

Novelty/Originality of this study: Identifying the women at risk would allow us to follow them up during their pregnancy, recognize earlier symptoms of pregnancy-related anxiety as they develop, and implement therapeutic interventions if needed, and spouse's training may also be encouraged and planed.

Keywords: Pregnancy-related Anxiety, Couple Relationship, Satisfaction, Subjective, Happiness, Pregnant Women.

\section{INTRODUCTION}

In a women's life, pregnancy is a time of transition marked by changes in cognition, emotion, physical changes, and also in social functioning, so it is understandable that expectant mothers are also worried about their future. Feeling any anxiety in pregnancy is perfectly common. For women and their families, childbirth is a period of transition and adaptation, and they face many normal worries during this time. Around this time, it is natural for pregnant women to worry about unborn baby health, baby delivery, and responsibilities after the birth of a child. If a pregnant woman doesn't have spouse or family support and unplanned pregnancy these issues may be heightened. However, researchers often refer to pregnancy-related issues as pregnancy-specific anxiety, which may lead to a high degree of anxiety (Hoyer, Wieder, Höfler, Krause, Wittchen \& Martini, 2020).

Pregnancy-related anxiety has grown as one of the most important psychological indicators of serious adverse birth results and is also involved in developing weaker infants and children. Pregnancy anxiety is a relatively new emerging term in maternal and newborn health-related research, and there is no agreement yet about how adequately to define and quantify it (Schetter \& Guardino, 2014).

In this research, an effort was created to examine the association between pregnancy-related anxiety and couple relationship satisfaction; with subjective happiness of pregnant women. Pregnancy-related anxiety is an emotional state similar to state anxiety but different since, in the sense of their pregnancies, it is primarily rooted in fears among pregnant women (Cameron, Giesbrecht \& Tomfohr-Madsen, 2021). According to Schetter and colleagues (2014) first Standley, Soule, and Copans (1979) and Lederman (1984), designed interviews to evaluate prenatal anxiety and psychosocial problems during pregnancy. Lederman's work served as the basis for Dunkel Schetter and colleagues' research on pregnancy-related anxiety, which started in the 1980s.

Schetter (2011) described pregnancy-related anxiety as a negative emotional state that triggers worries about one's baby health and wellbeing, hospital, imminent birth, and health services (which include mothers health and pregnancy survival), delivery and postnatal, and function of parenting. Thus, anxiety linked to pregnancy can be considered an association between a woman's general susceptibility to stressful, emotional states and circumstances of her pregnancy. These conditions involve conditions of medical risk such as hypertension that may influence pregnancy outcomes, history of risks in prior 
pregnancies or births, as well as psycho-social considerations such as whether or not the pregnancy was expected, absence of preventive care, access to social support, low income and absence of other resources. For instance, during pregnancy, women with a high degree of trait anxiety can be hypersensitive and likely to sense unclear stimuli as threatening, such as inconclusive test results, or bodily symptoms such as cramping.

Specific anxiety related to pregnancy is described as worries, pregnancy fears, and related concerns, delivery of a child, newborn health, and worries related to the future functioning of parenting (Huizink, Mulder, Robles de Medina, \& Visser, 2004). Throughout pregnancy, elevated degrees of PSA were noticed in the initial trimester and last pregnancy trimester, and decreased level of anxiety in the 2nd trimester presented a U shape pattern (Lee et al., 2007 \& Teixeira et al., 2009). Evidence suggested that the determinants of anxiety during pregnancy and postnatal phase are lack of care and weak marital relations, disappointment from family, and very low social supports from others (Karacam \& Ancel, 2009, Rubertsson et al., 2014). The younger age pregnant women have high levels of anxiety related to pregnancy, corresponding with documented studies (Arch, 2013; Henderson \& Maggie, 2013).

Pregnancy presents a period of intense change, such as physical change, physiological change, and psychological change can increase women's susceptibility to anxiety (Wenzel, 2011). According to Guardino and Schetter (2014), some conditions such as a high-risk health condition or an unwanted pregnancy with insufficient help from the father of an infant can be sufficiently dangerous to cause anxiety even in women who are not normally anxious. Research showed that a pregnant woman positively reacts to a body change when they have planned and wanted pregnancy which leads them to feelings of happiness or joy and fulfilment (Skouteris \& Werthimer, 2003).

A feeling that women are pregnant and will soon be rewarded with a baby will give women who are expecting a child great happiness and joy. Therefore these serve as a crucial motivator in the first place to maintain the pregnancy. A woman wants that her happiness to increase and hence continue to have the baby; however, as the time of pregnancy goes on, and women begin to have a physiological change, environmental change, and psychological changes, there is also a shift in her mood that can affect the level of her happiness. Overall happiness is described as the person's ability to judges the quality of life as a whole (Veenhoven, 1984). Thus subjective happiness emerges as an attitude towards one's own life, which has its own and includes related feelings and beliefs. According to Dutt and Radcliff (2009), subjective happiness is a specific emotion. It is an overall judgment made by a person in the recent past to account for both his enjoyable and unpleasant experiences.

\section{Rationale}

The major purpose of the current research was to study the effect of pregnancy-related anxiety on subjective happiness in pregnant women of Pakistan. Previous studies on anxiety linked to pregnancy found that gestation-related anxieties were the true indicators of unfavourable outcomes of labour than anxieties that are general. There are minimal proof present on particular issues, and pregnancy concerns, anxieties related to pregnancy nature and their effects on pregnancy results need future research investigating anxieties related to pregnancy and their risk factor in expectant mothers (Bayrampour, Heaman, Duncan, \& Tough, 2013).

The findings of the present study will contribute significantly to clinical psychology. The findings will give a chance to approach those expectant mothers who might benefit from assessment and coping with pregnancy-related anxiety. Identifying the women at risk will also help us to monitor them throughout their pregnancy and identify earlier signs of pregnancy-related anxiety when they develop and then, if necessary, incorporate therapeutic measures and may also promote and schedule spouse training.

\section{Objectives of the study}

Given the above details, the following are the objectives of the present study.

1. To examine the relationship between pregnancy-related anxiety and subjective happiness among pregnant women.

2. To examine the relationship between couple relationship satisfaction and subjective happiness among pregnant women.

3. To study the moderating role of couple relationship satisfaction between pregnancy-related anxiety and subjective happiness among pregnant women.

\section{LITERATURE REVIEW}

Pregnant women were influenced positively and negatively, based on variations that occurred during the trimester of Pregnancy (Chang, Chao, \& Kenney, 2006). Turk, Sakar, and Earkaya (2016) studied the degrees of happiness of the expectant mothers included in the research were analyzed and reported to be greater in pregnancy. They concluded that expectant mothers should be motivated to engage in activities that enhance their happiness and participate in pregnancy training programs. The presence of the partner may also be promoted into this training. It should also enhance mother-baby 
relationships and interaction among couples. They also concluded that a wanted pregnancy progresses to happiness, fulfilment, and women responding to their body changes positively.

Personal relationships are fundamental to being human, and an intrinsic and biological aspect of human behaviour is the creation of these relationships (Guerrero, Anderson, \& Afifi, 2011). Interpersonal relationship research is becoming increasingly relevant because it is present in all facets of human life and has been shown to significantly affect the way individuals live. Evidence has actually been found to demonstrate the strong, stable relationships are related to improved mental and physical health (Guerrero, Anderson, \& Afifi, 2011). According to Rusu and Muresan (2014), couple relationship satisfaction is generally characterized as the emotional state of the person being happy with the relationship, aspirations, and experiences regarding a couple's life.

Hamid, Asif, and Haider (2008) conducted a study to discover the anxiety symptoms frequency during the time of pregnancy, they found that women with pregnancy feel more anxiety as compared to their evenly resembled counterparts, and many of them are not monitored during the period. They concluded that the diagnosis, referral, and treatment of anxiety during pregnancy requires further efforts.

One research was performed on stable pregnant nulliparous women with marital distress referred for assessing anxiety during pregnancy to health care centres. For marital satisfaction, women with an anxiety history at the time of pregnancy are evaluated. Parents care programmes are recommended, including pregnant mothers screening dependent on relationship satisfaction, considering the predictive impact of relationship satisfaction on anxiety in pregnancy. It was concluded that the spouse's relationship would be a core concern for health professionals, especially midwives, during Pregnancy (Salehi \& Shahhosseini, 2017).

According to Salehi and Shahhosseini (2017), the predictive anxiety factor is couple relationship satisfaction during pregnancy. Marital satisfaction of couples has a vital role in the psychological health of women. Psychologically healthier women can create an effective interaction with her past experiences and handle her worry and depression. Marital disagreements are expressed in certain individuals by psychological symptoms and signs such as violent behaviours and worry. Also, the formation of an acceptable emotional partnership between spouses is disturbed by low marital satisfaction, which enhances the anxiety level. In health care services, offering therapy services for pregnant women and creating a healthy marital atmosphere and supportive and acceptable relationship of couples may help expecting mothers to cope with emotional stresses during pregnancy.

During the antenatal phase, a bilateral connection is available among_relationship satisfaction and psychological issues. It is assumed that women with low relationship satisfaction develop a high level of worry in pregnancy. During pregnancy, physically and mental changes may influence women's sexuality and relationship characteristics. Thus, in the starting month of pregnancy, female's sexual issues increase, and after baby birth return to normal range. However, concerning the connection between anxiety and marital satisfaction during pregnancy, there are contradictions in the result of the studies. Some researchers have shown that as relative to healthy females, those expecting mothers who develop an anxiety disorder during pregnancy or in the postnatal period may not suffer from sexual issues further (Salehi \& Shahhosseini, 2017; Zhou, Weng, Tan, Wu, Ma, Zhang, \& Yuan, 2020).

The research conducted by Babanazari and Kafi (2008) showed that marital happiness is a predictor for assessing pregnancyrelated anxiety. The research showed that some transitions are supposed low or increased and then again increased pregnancy-related anxiety during $1^{\text {st }}$ pregnancy trimester. Still, poor pregnancy information, high relationship satisfaction play major and highly important roles in understanding the difference in pregnancy-related anxiety instead of being at a particular time of gestation. Their studies found that relationship satisfaction is a very strong predictive variable of anxiety related to pregnancy. With greater relationship satisfaction, anxiety will be low; this relation certainly demonstrates the vital partner role in modifying and exacerbating anxiety related to pregnancy. The partner's torturing and painful relationship can increase psychological disorders of women at the time of gestation.

During gestation, the strongest predicting variable of anxiety and mental health-related issues is poor marital relationships. The important component that affects women's adaptability to mental pressures is the spouse's emotional support and stable marriage atmosphere at this time. Not feeling love for family and generally, the disorder in a couple's relationship will elevate anxiety, aversion to gestation, and ultimately the psychological wellbeing of the pregnant (Babanazari \& Kafi, 2008; Lee, Kim, \& Lee, 2021).

Stapleton, Westling, Schetter, Glynn, Rini, Hobel, et al. (2012) research showed that perceived help by a partner in gestation is an indicator of a mother's mental wellbeing. Some studies have shown a strong association between anxiety related to pregnancy and marriage satisfaction; Rini, Sandman, Glynn, Hobel, and Schetter (2006), research shown that women be pleased with effective protection to show a low level of anxiety during mid of gestation and decreased amount of anxiety during mid to last period of gestation. Moreover, the researches showed that relative to those with less negative relationship, 
women with a less positive relationship with spouse experience greater anxiety; in reality, the partner relationship impacts psychological adjustment at the time of change to parenthood of both the women/men (Figueredo, Field, Diego, HernandezReif, Deeds, \& Ascencio 2008; Ilska, Brandt-Salmeri, \& Kołodziej-Zaleska, 2020).

Most of the research carried out in this area deals with the impact on the pregnancy of negative emotions such as fear, worry, and distress, and having no proof of health effects like happiness and related factors. There was no proof of satisfaction during pregnancy despite a comprehensive quest for similar research.

\section{Hypotheses}

The hypotheses of the current study are as follows:

1. Pregnancy-related anxiety will negatively predict the subjective happiness of pregnant women.

2. Couple relationship satisfaction will positively predict the subjective happiness of pregnant women.

3. Couple relationship satisfaction moderates the relationship between pregnancy-related anxiety and subjective happiness among pregnant women.

\section{METHOD}

\section{Research design}

The current study was cross-sectional based on the survey method.

\section{Sample}

Participants of the present study were comprised of pregnant women $(N=30$ (pilot study), $\mathrm{N}=200$ (main study)) ages range from 18 to 35 years old from hospitals of the Hazara division. Data was gathered by using the purposive sampling technique. Written informed consent was taken before scale administration.

Inclusion Criteria: Following inclusion criteria were used.

1. Willing women in the age group of 18-35 years with low-risk pregnancy was selected.

2. Pregnant women with first, second, and third trimesters were selected.

3. Both first-time pregnant and second pregnancy was approached.

4. Literate and Illiterate pregnant women were selected.

5. Women with miscarriages were also approached.

Exclusion Criteria: Following inclusion criteria were used.

1. Those pregnant women having moderate and high-risk pregnancies were excluded.

\section{Instruments}

Demographic Sheet: The demographic sheet was comprised of age, education, pregnancy $\left(1^{\text {st }}, 2^{\text {nd }}, 3^{\text {rd }}\right.$, or precious child pregnancy), duration of the marriage, previous miscarriage, planned or unplanned, gyne complications (serious physical or psychological illness), number of children, preference for gender (by mother, by father, by in-laws) and family system.

Anxiety Scale for Pregnancy: The anxiety Scale for Pregnancy was developed by Doyle-Waters (1994). This scale consists of 14 items (7 positive and 7 negative items), with items response ranging from "not at all" (1 item) to "very much" (4 items). Positive items have reversed scoring, ranged from 14 to 56. The scale consist of 5 subscales: the baby (items 1, 6, 12), labor (items 2, 5, 14), marital (items 8,10,11), attractive (items 3, 13), and support (items 4, 7, 9). All subscales comprised 3 items except the attractive factor. The Cronbach alpha reliability is .76. High scores on the scale indicate a high rate of pregnancy anxiety, and low scores indicate a low level of pregnancy anxiety.

ENRICH Couple Satisfaction Scale (CSS): For measuring the quality of marital relationships, the ENRICH Couple Satisfaction Scale (Olson \& Larson, 2008) was used. The scale was originally developed by Fowers and Olson (1993), consisting of 15 items. Afterward, the revisions of the scale were also put forth, and the latest revision of this scale was given by Olson and Larson (2008). In the current study, the latest revision of the instrument (10-item version of the scale) as suggested by the authors was used. The scale consists of positive items (items $1,3,4,7$, and 9) and 5 negative items (items 2 , 5, 6, 8, and 10). This scale is translated by Nazia Iqbal (2013) in Urdu. It is a 10-item scale based on a 5-point Likert scale. The responses range from 1 to 5 , i.e., $1=$ Strongly disagree to $5=$ Strongly agree. For measuring the quality of the marital relationship, the negative items were reverse coded, and then a composite score was obtained. The alpha reliability of the 
original scale was .88. High scores on the scale showed a high level of couple relationship satisfaction, and low scores indicate a low level of couple relationship satisfaction.

Subjective Happiness Scale-Urdu (SHS-U): The Subjective Happiness Scale was originally developed by Lyubomirsky and Lapper (1999) and translated into Urdu by Warda Ishfaq, used to evaluate one's subjective happiness and 4 items. For all 4 items of SHS-U, the values of the correlation coefficient range from .54 to .78 . Cronbach alpha reliability is .88 and splithalf reliability .85. High scores on the scale show a high level of happiness, and low scores indicate a low level of happiness.

\section{Proposed Data Analysis}

Data were analyzed by using SPSS 23. The statistical analyses of correlation, regression, t-test, and ANOVAs were used.

\section{Ethical Considerations}

The research followed all the ethical principles of psychological research. Written informed consent was taken from the participants, and the researcher was ensured regarding privacy and confidentially of the information obtained from the participants.

\section{Procedure}

In this study, the researcher personally addressed the participants to gather the data. From hospital authorities' written permission was obtained to collect the data from participants. Participants told participants' nature, intentions, and significance, and informed consent was taken before scale administration. The respondent with voluntary participation was not be provided with any compensation for participation. The researcher responded to the queries of participants before, during, and after the form completion. In the end, the researcher appreciated and thanks to the respondents for their valuable participation in the study.

\section{RESULTS}

Table 1: Frequencies and percentages of demographic variables of Study $(\mathrm{N}=200)$

\begin{tabular}{llll}
\hline Variables & Category & $\boldsymbol{f}$ & $\mathbf{\%}$ \\
\hline Age & Below 25 & 89 & 31.0 \\
\hline & Above 25 & 111 & 69.0 \\
\hline Pregnancy & First & 71 & 35.5 \\
\hline & Second & 51 & 25.5 \\
\hline Third & 78 & 39.0 \\
\hline muration of & Less than 5 years & 125 & 62.5 \\
\hline Child birth & More than 5 years & 75 & 37.0 \\
\hline & With family planning & 116 & 58.0 \\
\hline & Without family & 84 & 42.0 \\
\hline Gyane & Planning & & \\
\hline Complications & Physical & 143 & 71.5 \\
\hline Mother priority & Psychological & 57 & 28.5 \\
\hline & Boy & 104 & 52.0 \\
\hline Husband priority & Girl & 96 & 48.0 \\
\hline & Goy & 79 & 39.5 \\
\hline In-laws priority & Boy & 121 & 60.5 \\
\hline & Girl & 111 & 55.5 \\
\hline Trimester & First & 88 & 44.0 \\
\hline & Second & 37 & 18.5 \\
\hline & Third & 75 & 37.5 \\
\hline Miscarriage & Yes & 88 & 44.0 \\
\hline & No & 56 & 28.0 \\
\hline
\end{tabular}

Table 1 shows the frequency and percentage of pregnant women concerning age, pregnancy, duration of the marriage, childbirth, gyne complications, mother priority, husband priority, in-laws priority, trimesters, and miscarriage. 
Table 2: Psychometric Properties of the Study Major Variables/Scales (N=200)

\begin{tabular}{llllllll}
\hline \multicolumn{7}{c}{ Range } \\
\hline Variables & $\boldsymbol{K}$ & $\boldsymbol{\alpha}$ & $\boldsymbol{M}(\boldsymbol{S D})$ & Potential & Actual & Skew & Kurt \\
\hline ASP & 14 & .82 & $38.64(6.93)$ & $14-70$ & $14-52$ & 0.06 & 0.60 \\
\hline SHS & 4 & .73 & $17.24(5.26)$ & $4-28$ & $4-26$ & 0.30 & 0.20 \\
\hline ECRS & 10 & .70 & $25.64(3.99)$ & $10-50$ & $14-35$ & 0.42 & 0.22 \\
\hline
\end{tabular}

Note. ASP = Anxiety Scale for Pregnancy; $\mathrm{SH}=$ Subjective Happiness Scale; ECRS= ENRICH Couple Relationship Satisfaction Scale.

Table 2 shows the psychometric properties of study variables. The reliability analysis showed that the reliability coefficient of all scales has satisfactory internal consistency.

Table 3: Correlation of study variables $(\mathrm{N}=200)$

\begin{tabular}{ccccc}
\hline & Variables & $\mathbf{1}$ & $\mathbf{2}$ & $\mathbf{3}$ \\
\hline 1 & PRA & - & $-.23^{* *}$ & $-.18^{* *}$ \\
\hline 2 & $\mathrm{CRS}$ & & - & $.18^{* *}$ \\
\hline 3 & $\mathrm{SH}$ & & & - \\
\hline
\end{tabular}

Note. ${ }^{* *} \mathrm{p}<.01$ Correlation is significant at the 0.01 level (2-tailed).

Table 3 shows Pearson correlation among study variables. The findings indicate that Pregnancy related Anxiety has significant negative correlation with Couple relationship satisfaction $(r=-.23, p<.01)$ and Subjective happiness $(r=-.18, p$ $<.01)$. Couple relationship satisfaction has significant positive correlation with subjective happiness $(\mathrm{r}=.18, \mathrm{p}<.01)$.

Table 4: Simple Linear Regression showing Pregnancy-related Anxiety as Predictor of Subjective Happiness (N=200)

\begin{tabular}{lccccc}
\hline & $\boldsymbol{B}$ & $\boldsymbol{S E B}$ & $\boldsymbol{B}$ & $\boldsymbol{T}$ & $\boldsymbol{p}$ \\
\hline Constant & 11.80 & 2.094 & & 5.636 & .000 \\
\hline SH & .141 & .053 & -.184 & 2.637 & .009 \\
\hline
\end{tabular}

Note. $\mathrm{R}=-.184, \mathrm{R}^{2}=.129$

In table 4 linear regression analysis is computed with Pregnancy related Anxiety as predictor variables subjective happiness as the outcome variable. The findings indicate that pregnancy-related anxiety has a significant negative effect on the subjective happiness of pregnant women.

Table 5: Simple Linear Regression showing Couple Relationship Satisfaction as Predictor of Subjective Happiness (N=200)

\begin{tabular}{lccccc}
\hline & $\boldsymbol{B}$ & $\boldsymbol{S E B}$ & $\boldsymbol{B}$ & $\boldsymbol{T}$ & $\boldsymbol{p}$ \\
\hline Constant & 23.47 & 2.403 & & 9.769 & .000 \\
\hline CRS & .243 & .093 & .183 & 2.625 & .009 \\
\hline
\end{tabular}

Note. $\mathrm{R}=.183, \mathrm{R}^{2}=.129$

In table 5 linear regression analysis is computed with Couple Relationship Satisfaction as predictor variables subjective happiness as the outcome variable. The findings indicate that Couple Relationship Satisfaction has a significant positive effect on the subjective happiness of pregnant women.

Table 6: Moderating effect of CRS on Pregnancy-related Anxiety and Subjective Happiness among pregnant women $(\mathrm{N}=200)$

\begin{tabular}{lllllll}
\hline Variables & B & SE & T & P & \multicolumn{2}{c}{ 95\% C I } \\
& & & & \multicolumn{2}{c}{ [LL-UP] } \\
\hline (Constant) & 17.27 & .38 & 45.58 & .00 & 16.52 & 18.01 \\
\hline Pregnancy related Anxiety (IV) & .12 & .06 & 2.11 & .04 & .01 & .23 \\
\hline CRS (Moderator) & -.20 & .10 & -2.10 & .04 & -.39 & -.01 \\
\hline $\begin{array}{l}\text { Pregnancy related Anxiety x CRS } \\
\text { (IV x Moderator) }\end{array}$ & .00 & .01 & .28 & .78 & -.03 & .03 \\
\hline
\end{tabular}

Note. $* * * \mathrm{P}<.001$ 
Table 6 shows the moderating impact of CRS on ASP and SHS. Results indicate that CRS B $=-.20(t=-2.10, p>.04)$ and ASP B $=.12(t=2.11, \mathrm{p}>.04)$ predict SHS significantly. Results also indicated non-significant moderation impact of CRS on ASP and SHS, with B $=.00(\mathrm{t}=.28, \mathrm{p}=\mathrm{n} . \mathrm{s})$ at $95 \%$ confidence interval. As evident through analysis, CRS does not moderate the relationship between ASP and SHS. However, CRS predicts SHS significantly, but in the presence of ASP, it predicts SHS non-significantly. Hypothesis number 3 is not supported by the present data.

\section{DISCUSSION}

The sample of the present study has consisted of 200 pregnant women from Abbottabad, Haripur, and Wah Cantt. The age of the sample ranged from 18 to 35 years.

The first hypothesis, "pregnancy-related anxiety will predict subjective happiness among pregnant women" is supported in the current study. The current findings are similar to the previous research that showed that pregnancy-related anxiety has a relationship with subjective happiness. Childbearing has large effects on mother happiness of mother on the birth of the first child, a greater effect on the happiness of father also observed if the firstborn is a boy and an additional positive influence on happiness if the mother has a supportive spouse (Kohler, Behrman, \& Scythe, 2005). One research analyzed reports on the relationship between communication skills and pregnancy anxiety and found that significant proportions of health issues are physical during the time of pregnancy, including Anxiety disorders. On another hand, building a strong family relationship and good communication skills are important. Being parents is a very enjoyable experience in the life of those partners who love communication skills. Partners and their children's high levels of psychological health and healthy spouse relationships can have a protective impact on stressors like pregnancy anxiety (Malary, Shahhosseini, Pourasghar, \& Hamzehgardeshi, 2015).

According to Salehi and Shahhosseini (2017) in addition, the formation of an acceptable emotional partnership between spouses is disturbed by low marital satisfaction, which in turn enhances the anxiety level. Turk, Sakar, and Earkaya (2016) studied the degrees of happiness of the expectant mothers included in the research were analyzed and reported to be greater in pregnancy. They concluded that expectant mothers should be motivated to engage in activities that enhance their happiness and participate in pregnancy training programs. The presence of the partner may also be promoted into this training. It should also enhance mother-baby relationships and interaction among couples. They also concluded that a wanted pregnancy progresses to happiness, fulfilment, and women responding to their body changes positively.

The second hypothesis, "Couple relationship satisfaction will positively predict subjective happiness of pregnant women". The current findings are similar to the prior research that show Couple relationship satisfaction will positively predict subjective happiness. According to Salehi and Shahhosseini (2017), the predictive anxiety factor is couple relationship satisfaction during pregnancy. Marital satisfaction of couples has a vital role in the psychological health of women. Psychologically healthier women can create an effective interaction with her past experiences, and she can handle her worry and depression. Marital disagreements are expressed in certain individuals by psychological symptoms and signs such as violent behaviours and worry feelings. In addition, the formation of an acceptable emotional partnership between spouses is disturbed by low marital satisfaction, which enhances the anxiety level. In health care services, offering therapy services for pregnant women and creating a healthy marital atmosphere and supportive and acceptable relationship of couples may help expecting mothers to cope with emotional stresses during a time of pregnancy.

Gestation is a condition that causes a wide variety of changes like physical changes mental and social changes in women. Pregnant women's expectations and attitudes about pregnancy are necessary because of their effect on the person's mood and mental health. For mentally stable women, pregnancy is the representation of self-actualization and female identity. For many pregnant women, gestation is a special experience and, they feel satisfied during the time of Pregnancy (Jannati \& Khaki, 2005).

According to Salehi and Shahhosseini (2017), the predictive anxiety factor is couple relationship satisfaction during pregnancy. Marital satisfaction of couples has a vital role in the psychological health of women. Psychologically healthier women can create an effective interaction with her past experiences and handle her worry and depression. Marital disagreements are expressed in certain individuals by psychological symptoms and signs such as violent behaviours and worry feelings. In addition, the formation of an acceptable emotional partnership between spouses is disturbed by low marital satisfaction, which in turn enhances the anxiety level. In health care services, it seems that offering therapy services for pregnant women and creating a healthy marital atmosphere and supportive and acceptable relationship of couples may help expecting mothers to cope with emotional stresses during the time of pregnancy.

During the antenatal phase, a bilateral connection is available among_relationship satisfaction and psychological issues. It is assumed that women with low relationship satisfaction develop a high level of worry in pregnancy. In addition, during pregnancy, biological, physical, and mental changes may influence women's sexuality and relationship characteristics. Thus, in the starting month of pregnancy, female's sexual issues increase, and after baby birth return to normal range. However, 
with respect to the connection between anxiety and marital satisfaction during pregnancy, there are contradictions in the result of the studies. Some researchers have shown that as relative to healthy females, those expecting mothers who develop an anxiety disorder during pregnancy or in the postnatal period may not suffer from sexual issues further (Salehi \& Shahhosseini, 2017).

The third hypothesis "Couple relationship satisfaction moderating the relationship between pregnancy-related anxiety and subjective happiness among pregnant women". The current findings are not similar to the prior research, which shows that couple relationship satisfaction moderating the relationship between pregnancy-related anxiety and subjective happiness (Jayasvasti, 2005). Moreover, the presented study suggested conducting future studies with a large sample size to identify culturally-based differences relevant to Pakistan because the perception of couple relationship satisfaction, Pregnancy-related anxiety, and happiness may change due to cultural or subjective aspects.

\section{IMPLICATIONS}

The present study's findings supported the existing literature on Spielberger's theory and made a significant contribution to prior literature. In prior research, variables were studied in individualistic culture; this study confirms the finding of prior research in a collectivistic culture. The study grasps applied significance for pregnant women of collectivistic culture. The study's findings give practical suggestions to improve pregnancy-related anxiety and the importance of couple relationship satisfaction and subjective happiness among pregnant women.

\section{CONCLUSION}

The main objectives of the present study were to examine the relationship between pregnancy-related anxiety, couple relationship satisfaction, and subjective happiness among pregnant women. Also, to study the moderating role of couple relationship satisfaction between pregnancy-related anxiety and subjective happiness among pregnant women and examine the differences in pregnancy-related anxiety, couple relationship satisfaction, and subjective happiness across various demographic variables. In the current research, most of the hypotheses were supported. Results suggested that there is a strong relationship between study variables. The present study is pretty insightful in understanding the role of Couple relationship satisfaction in predicting pregnancy-related anxiety and subjective happiness among pregnant women.

\section{LIMITATION AND FUTURE STUDY}

In the current research, some limitation is also found. The first limitation in the present study is that data was obtained through self-report measures, which are important for social attractiveness, single-source bias, and common process variance. Thus in the future study, data should be cross-rated through some other sources.

Due to time and economic constraints, the sample taken was small. Sample size can be enhanced in further studies, and it can also be extended to other locales of Pakistan.

\section{ACKNOWLEDGEMENT}

In the name of Allah, the Most Gracious and the Most Merciful Saying of Prophet Muhammad (PBUH) 'A person who is not thankful to his benefactor is not thankful to ALLAH'. My deep sense of gratitude is due to Allah (S.W.T), Who enabled me to complete this study. I appreciate those who directly or indirectly contributed to this Research.

\section{AUTHOR AND CO-AUTHORS CONTRIBUTION}

Author: Miss Saira Bano presented her research idea, wrote abstract, introduction, methodology, conducted analysis, generated tables during analysis.

Co-Author: Dr. Nazia Iqbal supervised this study.

Co-Author: Miss Andleeb Akhtar analyzed the data.

Co-Author: Mr. Sajid M. Alvi created the idea, design, and composition of the article.

Co-Author: Aaliya Zaka has reviewed the article.

\section{REFERENCES}

1. Arch, J. J. (2013). Pregnancy-specific anxiety: Which women are highest and what are the alcohol-related risks? Comprehensive Psychiatry, 54 (3), 217-228. https://doi.org/10.1016/j.comppsych.2012.07.010

2. Babanazari, L., Kafi, M. (2008). Relationship of pregnancy anxiety to its different periods, sexual satisfaction and demographic factors. Iranian Journal ofnPsychiatry and Clinical psychology, 14(2), 206-213.

3. Bayrampour, H., Heaman, M., Duncan, K.A., Tough, S. (2013). Predictors of perception of pregnancy risk among nulliparous women. Journal of Obstetric, Gynecologic, and Neonatal Nursing, 42 (4), 416-427. https://doi.org/10. $\underline{1111 / 1552-6909.12215}$ 
4. Cameron, E. E., Giesbrecht, G. F., \& Tomfohr-Madsen, L. M. (2021). Psychometric properties of the PregnancyRelated Anxiety Scale for use with fathers during pregnancy. Psychology of Men \& Masculinities, 22(1), 26-38. https://doi.org/10.1037/men0000260

5. Chang, S., Chao, Y., \& Kenney, N.J. (2006). I am a woman and I'm pregnant: Body image of woman in third trimester of Pregnancy, Birth, 33(2),147-153. https://doi.org/10.1111/j.0730-7659.2006.00087.x

6. Dutt, A. K. \& Radcliff, B. (2009). Happiness, Economics and Politics: Towards a Multi- Disciplinary Approach (11th ed). Edward Elgar Publishing, Cheltenham.

7. Figueiredo, B., Field, T., Diego, M., Hernandez-Reif, M., Deeds, O., Ascencio, A. (2008). Partner relationships during the transition to parenthood. Journal of Reproductive and Infant psychology, 26(2), 99-107. https://doi.org/10.1080/02646830701873057

8. Guerrero, L. K., Anderson, P. A., \& Afifi, W. A. (2011). Close Encounters: Communication in Relationships (3rd ed.). Los Angeles: Sage. https://trove.nla.gov.au/work/25631380

9. Henderson, J., \& Maggie, R. (2013). Anxiety in the perinatal Perio: Antenatal and postnatal influences and women's experience of care. Journal of Reproductive and Infant Psychology, 31(5), 465-478, https://doi.org/10.1080 102646838.2013.835037

10. Hamid, F., Asif, A., \& Haider, I. I. (2008). Study of anxiety and depression during pregnancy. Pakistan Journal of Medical sciences, 24(6), 861-864.

11. Hoyer, J., Wieder, G., Höfler, M., Krause, L., Wittchen, H.-U., \& Martini, J. (2020). Do lifetime anxiety disorders (anxiety liability) and pregnancy-related anxiety predict complications during pregnancy and delivery? Early Human Development, 144, 105022. https://doi.org/10.1016/j.earlhumdev.2020.105022

12. Huizink, A. C., Robles de Medina, P. G., Mulder, E. J. H., Visser, G. H. A.,Stapleton, L. R. T., Schetter, C. D., Westling, E., Rini, C., Glynn, L. M., \& Hobel, C. J., et al. (2012). Perceived partner support in pregnancy predicts lower maternal and infant distress. Journal of Family Psychology, 26(2), 453-459. https://doi.org/10.10 37/a0028332

13. Ilska, M., Brandt-Salmeri, A., \& Kołodziej-Zaleska, A. (2020). Effect of prenatal distress on subjective happiness in pregnant women: The role of prenatal attitudes towards maternity and ego-resiliency. Personality and Individual Differences, 163, 110098. https://doi.org/10.1016/j.paid.2020.110098

14. Jannati, Y., \& Khaki, N. (2005). Psychiatry in Midwifery. Tehran: Jameenegar Publisher, 144-145.

15. Jayasvasti, K., \& Kanchanatawan, B. (2005). Happiness and related factors in pregnant women. Journal of the Medical Association of Thailand, 88(4), 220-225.

16. Karacam, Z., Ancel, G. (2009). Depression, anxiety and influencing factors in Pregnancy: A study in a Turkish population. Midwifery, 25 (4), 344-356. https://doi.org/10.1016/j.midw.2007.03.006

17. Kohler, HP., Behrman, J. R., \& Scythe, A. (2005). Partner + Children = Happiness? The Effects of Partnerships and Fertility on Well-Being. Psychological Review, 31(3), 407-445. https://doi.org/10.1111/j.1728-4457.2005.00078.x

18. Lee, A. M., Lam, S. K., Sze Mun Lau, S.M., Chong, C.S., Chui, H.W., \& Fong, D.Y. (2007). Prevalence, course, and risk factors for antenatal anxiety and depression. Obstetrics and Gynecology, 110 (5), 1102-1112. https://doi.org/10.1097/01.AOG.0000287065.59491.70

19. Lee, M., Kim, Y. S., \& Lee, M. K. (2021). The Mediating Effect of Marital Intimacy on the Relationship between Spouse-Related Stress and Prenatal Depression in Pregnant Couples: An Actor-Partner Interdependent Model Test. International Journal of Environmental Research and Public Health, 18(2), 487. https://doi.org/10.339 0/ijerph18020487

20. Malary, M., Shahhosseini, Z., Pourasghar, M., \& Hamzehgardeshi, Z. (2015). Couples Communication Skills and Anxiety of Pregnancy: A Narrative Review. Journal of the Academy of Medical Sciences of Bosnia and Herzegovnia, 27(4), 286-290. https://doi.org/10.5455/msm.2015.27.286-290

21. Rini, C., Schetter, C. D., Hobel, C. J., Glynn, L. M., \& Sandman, C. A. (2006). Effective social support: Antecedents and consequences of partner support during pregnancy. Personal Relationships, 13(2), 207-229. https://doi.org/10.1111/j.1475-6811.2006.00114.x

22. Rubertsson, C., Hellstrom, J., Cross, M., \& Sydsjo, G. (2014). Anxiety in early Pregnancy: Prevalence and contributing factors. Archives of Womens Mental Health, 17(3), 221-228. https://doi.org/10.1007/s00737-013-0409$\underline{0}$

23. Rusu, A.S., \& Muresan, V. C., (ed.) (2014). Satisfaction in Couples: Research in the Psychobiology of sexuality. Ed. Grinta, Cluj-Napoca.

24. Salehi, F., \& Shahhosseini, Z. (2017) Association Between Women's Marital Satisfaction and Anxiety During Pregnancy. Iran Journal of Psychiatry Behavior Science, 11(3), 24-31. https://doi.org/10.17795/ijpbs-7937

25. Schetter, D. C., \& Guardino, C. (2014). Understanding pregnancy anxiety concepts, correlates and consequences. Zero to Three, 34(3), 12-21. 
26. Schetter, D. C. (2011). Psychological science on Pregnancy: Stress processes, biopsychosocial models, and emerging research issues. Annual Review of Psychology, 62, 531-558. https://doi.org/10.1146/a nnurev.psych.031809.130727

27. Skouteris, H., Carr, R., Wertheim, E.H., Paxton, S.J., Duncombe, D. (2005). A prospective study of factors that lead to body dissatisfaction during pregnancy. Body Image, 2(4), 347-361. https://doi.org/10.1016/j.bodyim.2005.09.002

28. Stapleton, L.R.T., Schetter, C. D., Westling, E., Rini, C., Glynn, L.M., Hobel, C.J., et al. Perceived partner support in pregnancy predicts lower maternal and infant distress. Journal of Family Psychology, 26(3), 453-457. https://doi.org/10.1037/a0028332

29. Turk, R., Sakar, T., \& Erkaya, R. (2017). The effect of pregnancy on happiness, Education, Health and ICT for a Transcultural World, Spain, 2016, Almeria: Elsevier. https://doi.org/10.1016/j.sbspro.2017.02.198

30. Veenhoven, R. (1984). Conditions of Happiness (1st ed). Netherlands, Erasmus University Rotterdam. https://doi.org/10.1007/978-94-009-6432-7_1

31. Wenzel, A. (2011). Anxiety symptoms during pregnancy and the postpartum period.

32. In anxiety in childbearing women: Diagnosis and treatment. (21-35). Washington: American Psychological Association. https://doi.org/10.1037/12302-001

33. Zhou, C., Weng, J., Tan, F., Wu, S., Ma, J., Zhang, B., \& Yuan, Q. (2020). Pregnancy-related anxiety among Chinese pregnant women in mid-late pregnancy under the two-child policy and its significant correlates. Journal of Affective Disorders, 276, 272-278. https://doi.org/10.1016/j.jad.2020.07.099 